\title{
Identifikasi Potensi Kampung Budaya Betawi Setu Babakan Sebagai Destinasi Wisata Pendidikan Yang Berkelanjutan
}

\section{(Identifying The Potensial Of Kampung Budaya Betawi Setu Babakan As A Sustainable Educational Tourism Destination)}

\author{
Irwan $^{1}$, Rusdin Tahir ${ }^{2}$, M Liga Suryadana ${ }^{3}$ Ute Lies Khadijah ${ }^{4}$ \\ ${ }^{1}$ Magister Pariwisata Berkelanjutan, Universitas Padjajaran, Indonesia \\ 2 Magister Pariwisata Berkelanjutan, Universitas Padjajaran, Indonesia \\ ${ }^{3}$ Sekolah Tinggi Pariwisata Bandung, Indonesia \\ ${ }^{4}$ Magister Pariwisata Berkelanjutan, Universitas Padjajaran, Indonesia \\ ${ }_{\text {email: irwan19003@mail.unpad.ac.id }}$
}

First received:

11 October 2020
Revised:

17 November 2020
Final Accepted:

29 December 2020

\begin{abstract}
Kampung Budaya Betawi Setu Babakan is a tourism destination established by the Provincial Government of DKI Jakarta as an effort to preserve and develop Betawi culture in a sustainable manner. The displacement of the native inhabitants of Jakarta due to the increase in population and the acculturation of immigrant culture has made Betawi culture forgotten. This is what encourages the Government to create a forum for the preservation of Betawi culture so that it continues to exist and develop. By using a qualitative descriptive method, the author tries to identify the potential of Kampung Budaya Betawi Setu Babakan as a destination for sustainable educational tourism. From this research, it was found that the various tourism activities found in the Betawi Cultural Village of Setu Babakan indicate that this area has the potential to be developed and is worthy of being used as a sustainable educational tourism destination in the Jakarta area.
\end{abstract}

Keywords : Tourism Potential; Betawi Culture; Setu Babakan; Sustainable Educational Tourism

\section{ABSTRAK}

Kampung Budaya Betawi Setu Babakan merupakan destinasi pariwisata yang didirikan oleh Pemerintah Provinsi DKI Jakarta sebagai upaya pelestarian dan pengembangan budaya Betawi secara berkelanjutan. Tergesernya penduduk asli Jakarta akibat bertambahnya jumlah penduduk dan dengan akulturasi budaya pendatang, membuat budaya Betawi mulai dilupakan. Hal inilah yang mendorong Pemerintah untuk menciptakan wadah pelestarian budaya Betawi agar tetap eksis dan berkembang. Dengan menggunakan metode deskriptif kualitatif, penulis berusaha mengidentifikasi potensi Kawasan Kampung Budaya Betawi Setu Babakan sebagai destinasi Wisata Edukasi Berkelanjutan. Dari penelitian ditemukan bahwa beragam aktivitas wisata yang terdapat di Kampung Budaya Betawi Setu Babakan menunjukkan bahwa daerah ini berpotensi untuk dikembangkan dan layak untuk dijadikan sebagai destinasi wisata edukasi berkelanjutan di wilayah Jakarta.

Kata kunci : Potensi Wisata; Budaya Betawi; Setu Babakan ; Wisata Edukasi Berkelanjutan

\section{PENDAHULUAN}

Indonesia sebagai negara kepulauan memiliki beragam seni dan budaya yang tersebar di seluruh wilayah Indonesia. Keberagaman seni dan budaya tersebut dijadikan sebagai daya Tarik wisata yang menarik banyak minat wisatawan baik wisatawan domestic ataupun wisatawan mancanegara yang tertarik untuk mengunjungi Indonesia. Untuk itu konsep pariwisata budaya menjadi suatu bagian yang penting yang dituangkan oleh pemerintah didalam Undang-undang No. 10 tahun 2009.

Diantara sekian banyak kebudayaan yang beragam tersebut yang menarik untuk dikunjungi adalah Kampung Budaya Betawi Setu Babakan yang terletak di daerah Srengseng Sawah Kecamatan 
Jagakarsa Jakarta Selatan. Ditetapkan sebagai Kawasan Wisata oleh Pemerintah Kota DKI Jakarta pada tanggal 20 Januari 2000, didirikannya Kampung Budaya Betawi bertujuan untuk menjaga eksistensi masyarakat Betawi di daerah pinggiran Jakarta sehingga Kampung Budaya Betawi Setu Babakan merupakan Kawasan yang dijadikan sebagai pusat kebudayaan masyarakat Betawi yang berusaha dilestarikan dan dijaga sebagai warisan budaya. Perkampungan Budaya Betawi Setu Babakan adalah sebuah tempat di wilayah Jakarta Selatan dimana ditempat ini pengunjung bisa menikmati suasana asri dan kehidupan sehari-hari masyarakat Betawi. Ditempat ini pengunjung akan dengan mudah menemukan tradisi masyarakat komunitas Betawi serta budayanya yang bisa dijadikan sebagai sumber informasi dan dokumentasi tentang kebetawian.

Di Kawasan ini pengunjungjuga dapat melihat beragam atraksi wisata serta kehidupan masyarakat Betawi sehari-hari yang didukung dengan pertunjukan-pertunjukan seni budaya betawi serta bangunan-bangunan khas budaya Betawi. Cara hidup khas masyarakat Betawi seperti bercocok tanam, memancing, berdagang, membuat kerajianan, dan membuat makanan khas Betawi masih dipertahankan ditempat ini sehingga menarik minat banyak wisatawan untuk berkunjung ketempat ini (Ngwira \& Kankhuni, 2018). Maryetti et al., (2016) dalam penelitiannya juga mengatakan banyak terdapat warung-warung yang menjajakan makanan khas Betawi di perkampungan ini. Destinasi pariwisata seperti Setu Babakan mengandalkan produk utama pariwisata sebagai mekanisme untuk menarik dan memotivasi wisatawan untuk mengunjunginya (Benur \& Bramwell, 2015) terutama untuk jenis wisata edukasi.

Keunikan serta keaslian seni-budaya dan keadaan ekosistem masyarakat setempat di Setu Babakan ini merupakan suatu hal yang dapat dijadikan sumber pengetahuan yang menarik untuk dikunjungi. Sesuai dengan apa yang dikatakan oleh Bodger (1998) didalam bukunya bahwa Wisata edukasi adalah suatu program dimana wisatawan melakukan kegiatan perjalanan wisata pada suatu tempat dalam suatu kelompok dengan tujuan utama mendapatkan pengalaman belajar secara langsung terkait dengan lokasi yang akan dikunjungi.

Saat ini telah banyak destinasi di seluruh dunia yang mulai menerapkan konsep pariwisata berkelanjutan sebagai suatu pendekatan yang dapat diadopsi di destinasi pariwisata. Fakta menunjukkan bahwa Pariwisata berkelanjutan menekankan pentingnya upaya kegiatan pariwisata agar dapat terhindar dari dampak negative baik secara ekonomi, social budaya dan juga lingkungan pada suatu destinasi (Pramusita \& Sarinastiti, 2018).

Melihat begitu banyaknya kegiatan dan atraksi budaya yang bisa dijadikan daya Tarik wisata oleh Kampung Budaya Betawi Setu Babakan membuat penulis tertarik untuk meneliti tentang potensi wisata kawasan ini dan sejauh mana aktivitas pariwisata dapat memberikan dampak positif bagi masyarakat. Studi ini bertujuan untuk menemukenali potensi wisata di Kampung Budaya Betawi Setu Babakan sebagai Destinasi Wisata Edukasi Berkelanjutan.

\section{METODE PENELITIAN}

Dalam penelitian ini menggunakan penulis menggunakan metode kualitatif deskriptif. Penelitian kualitatif digunakan untuk mencari tahu dan memahami secara mendalam suatu permasalahan atau fenomena yang umumnya berasal dari masalah sosial. Proses penelitian kualitatif dilakukan dengan mengumpulkan data yang spesifik termasuk data dari para partisipan, mengajukan pertanyan dan pprosedur-prosedur. Data tersebeut dianalisis secara induktif mulai dari tema-tema umum, dan kemudian menafsirkan makna dari data yang ada (Creswell, 2016). Data kualitatif adalah jenis data yang bukan dalam bentuk angka, melainkan suatu penjelasan atau uraian yang menggambarkan suatu keadaan, proses atau peristiwa tertentu. Melalui metode penelitian ini penulis berusaha mendeskripsikan tentang objek penelitian berdasarkan data dan fakta yang sebenarnya (Sekaran \& Bougie, 2016).

Sekaran \& Bougie, (2016) juga menyampaikan bahwa terdapat sumber data yaitu data primer dan data sekunder yang dapat memberikan informasi mengenai data tersebut. Dalam penelitian ini penulis menggunakan data sekunder yaitu data yang telah dikumpulkan oleh orang lain yang digunakan 
untuk tujuan lain selain untuk tujuan penelitian penulis saat ini. Beberapa sumber data sekunder tersebut adalah informasi terbitan yang tersedia baik dari dalam atau luar institusi, situs web, dan juga sumber internet seperti buletin statistic atau publikasi pemerintah. Kemudian data-data tersebut dianalisa oleh penulis secara deskriptif kualitatif, karena penelitian ini bertujuan untuk mendeskripsikan suatu gambaran yang jelas berkaitan dengan pokok permasalahan yang akan diteliti di daerah tersebut yaitu Identifikasi Potensi Kawasan Kampung Budaya Betawi Setu Babakan Sebagai Destinasi Wisata Edukasi Berkelanjutan.

\section{HASIL PENELITIAN DAN PEMBAHASAN}

\section{Profil Setu Babakan}

Setu Babakan terletak di kelurahan Srengseng Sawah Kecamatan Jagakarsa, Jakarta Selatan yang memiliki peranan sebagai pusat perkampungan budaya Betawi, sesuatu zona yang dilindungi untuk melestarikan peninggalan budaya asli Betawi yang dianggap sebagai budaya Jakarta. Setu Babakan merupakan suatu kawasan perkampungan yang diresmikan oleh Pemerintah DKI Jakarta sebagai tempat pelestarian serta pengembangan budaya Betawi secara berkesinambungan. Kawasan danau buatan dengan area seluas 32 hektar yang airnya berasal dari sungai Ciliwung ini sering digunakan untuk area pemancingan oleh masyarakat sekitarnya. Selain sebagai lokasi pemancingan, danau ini juga digunakan untuk sarana wisata seperti sepeda air atau sekedar bersepeda dan berolahraga mengelilingi tepian danau. Perkampungan yang terletak di selatan Kota Jakarta ini ialah salah satu daya Tarik wisata yang menarik untuk wisatawan yang ingin menikmati atmosfer dan suasana khas budaya Betawi asli secara langsung. Kampung Budaya Betawi Setu Babakan merupakan kawasan hunian yang mempunyai nuansa Betawi yang masih kokoh serta murni dari sisi budaya seperti seni pertunjukan, makanan tradisional, busana, rutinitas keagamaan, ataupun bentuk rumah adat Betawi.

Perkampungan yang luasnya 289 Hektar ini, 65 hektarnya merupakan lahan milik Pemerintah di mana yang baru dikelola baru sekitar 32 hektar. Perkampungan ini didiami paling tidak 3.000 kepala keluarga dengan sebagian besar warganya yang merupakan orang asli Betawi yang telah tinggal di wilayah tersebut secara turun temurun. Sebaliknya sebagian kecil yang lain merupakan para warga pendatang yang berasal dari daerah Jawa Barat, Jawa Tengah, Kalimantan serta daerah lain yang telah menetap di kampung ini lebih dari 30 tahun.

\section{Kekayaan Budaya Betawi}

Nama "Betawi" berasal dari kata "Batavia". Nama yang diberikan oleh Pemerintah Belanda pada zaman penjajahan dahulu. Orang-orang Betawi ini memang sudah menetap ditempat ini bahkan sebelum Jan Pieterzoon Coen membakar Jayakarta pada tahun 1619 dan mendirikan serta kota bernama Batavia tersebut.

Betawi merupakan suatu etnik dengan jumlah penduduk yang mendominasi Jakarta. Terbentuk sekitar abad ke-17, etnis ini merupakan hasil dari pencampuran beberapa suku bangsa seperti China, Arab, Sumatera, dan Bali, bahkan juga Portugis. Dari latar belakang budaya serta status sosial yang berbeda-beda, kelompok masyarakat ini mencoba mencari identitas bersama dalam bentuk lingua franca bahasa Melayu yang pada akhirnya terbentuklah masyarakat homogen secara alamiah (Pemerintah Provinsi DKI Jakarta, 2011).

Betawi ialah etnis yang kaya akan keragaman budaya, bahasa, serta kultur karena penduduk Betawi memiliki sifat majemuk yang berasal dari percampuran darah bermacam suku bangsa serta bangsa asing. Beberapa penelitian terdahulu tentang masyarakat Betawi menunjukkan bahwa kebudayaan Betawi memang sarat akan pengaruh dari etnis asing seperti Belanda, Tiongkok, Arab, India, Portugis meskipun ada etnis local lainnya yang juga ikut mewarnai seperti etnis yang berasal dari Sumatra, Jawa dan Sunda. Diketahui juga bahwa warna pakaian pengantin Betawi yang bercorak warna merah berasal dari budaya Tiongkok yang identic dengan warna merah dan begitu pula warna hijau 
merupakan pengaruh dari Islam yang berasal dari bangsa Arab. Dalam dialek Bahasa Betawi juga ditemukan kesan dialek Tionghoa, Belanda serta bahasa Arab yang diIndonesiakan.

\section{Potensi Wisata Edukasi di Setu Babakan}

Berdasarkan penelitian yang dilakukan oleh Rosmalia et al., (2019) bahwa Konsep perencanaan wisata yang dikembangkan pada kawasan Kampung Budaya Betawi Setu Babakan adalah destinasi pariwisata yang menjadikan atraksi kebudayaan Betawi sebagai aktivitas utamanya. Dari hasil penelusuran dan observasi yang dilakukan oleh penulis ditemukan banyak sekali kegiatan dan aktifitas wisata yang dapat dijadikan sebagai daya Tarik wisata edukasi, seperti :

1. Wisata Budaya

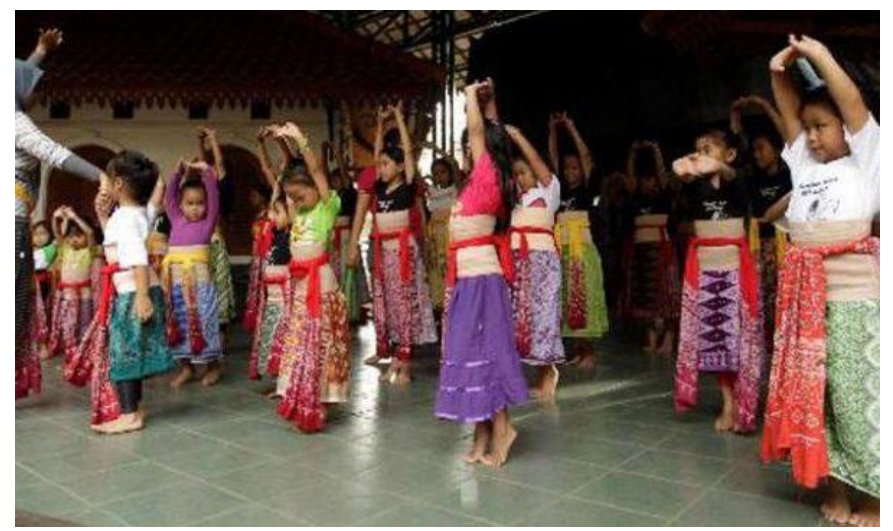

Gambar 1. Wisata Agro Setu Babakan

Sumber: http://www.setubabakanbetawi.com/

Menurut Spillane (2003) Jenis wisata budaya ditunjukan dengan adanya suatu keinginan atau motivasi wisatawan untuk mempelajari adat istiadat dan gaya hidup suatu masyarakat lain di pusat-pusat pengajaran serta Lembaga Penelitian. Aktivitas wisata di Kampung Budaya Betawi Setu Babakan dapat dikategorikan sebagai wisata budaya karena sebagian besar menggunakan unsur budaya sebagai daya tariknya sehingga wisatawan dapat menemukenali nilai-nilai budaya tradisional masyarakat betawi yang dikemas dengan baik sehingga layak ditampilkan serta disaksikan sebagai suatu pertunjukan yang memiliki nilai jual. Aktivitas wisata budaya yang dapat dinikmati secara langsung di Perkampungan Budaya Betawi Setu Babakan di antaranya adalah menyaksikan pertunjukan seni musik, seni tari dan teater yang dilakukan di area terbuka. Wisatawan juga dapat mengikuti pelatihan seni tari, seni musik, dan seni membatik. Mengikuti latihan silat Betawi dan seni teater tradisional serta melihat prosesi budaya masyarakat Betawi seperti acara aqiqah, khatam Qur'an, nujuh bulan, pernikahan, sunatan, prosesi injak tanah, ngederes, dan lain-lain.

\section{Wisata Agro}

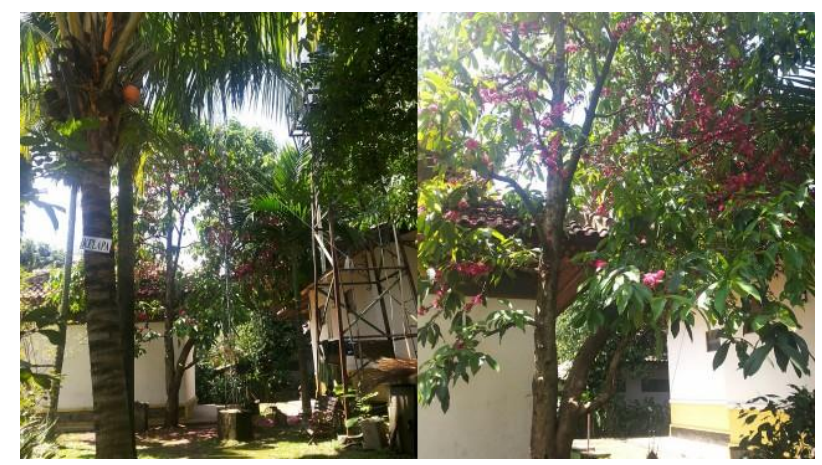

Gambar 2. Wisata Agro Setu Babakan

Sumber : https://sitifadlina.files.wordpress.com/ 
Berdasarkan definisi yang dikemukakan oleh Gil Arroyo et al. (2013), Wisata Agro atau agritourism dapat didefinisikan sebagai suatu kegiatan wisata terkait pertanian yang dilakukan di ladang tempat bekerja sehari-hari atau dilahan pertanian lainnya untuk tujuan hiburan atau Pendidikan. Dari definisi ini didapatkan kegiatan wisata edukasi yang dilakukan oleh Kampung Budaya Betawi Setu Babakan dengan tema pertanian yang sengaja dibuat untuk menarik minat wisatawan untuk belajar atau sekedar menikmati suasana diperkampungan tersebut.

Uniknya kegiatan wisata agro ini bukan dilakukan dilahan pertanian khusus melainkan berada diareal pelataran perkampungan dan dihalaman ruma-rumah penduduk sehingga wisatawan bisa mencoba memetik atau menikmati buah-buahan ini secara langsung. Terdapat beberapa jenis pepohonan yang bisa ditemui di Perkampungan Budaya Betawi, bahkan beberapa diantaranya sudah jarang ditemui seperti Mangga, Melinjo, Rambutan, Jambu, Kecapi, Jamblang, Krendang, Buni, Nangka, Cempedak, Nam-nam, Jambu Mede, Alpukat, Kwini, Bacang, Jengkol, dan Pete.

\section{Wisata Kuliner}

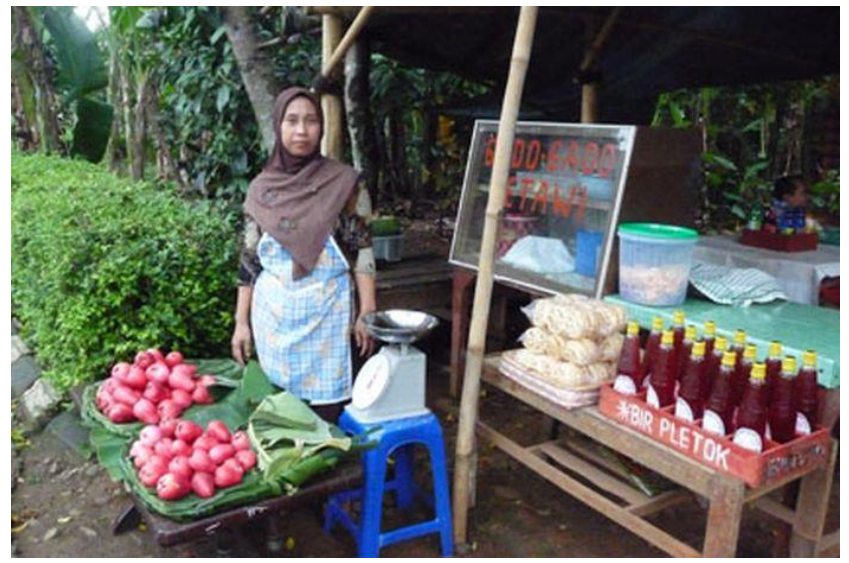

Gambar 3. Wisata Kuliner Setu Babakan

Sumber : https://asset-a.grid.id/

Menurut Santoso et al., (2019) makanan tradisional adalah makanan yang diolah dari bahan pangan hasil produksi masyarakat setempat, dengan proses yang telah dikuasai masyarakat dan hasilnya adalah produk yang citarasa, bentuk dan cara makannya dikenal, dan menjadi ciri khas dari kelompok masyarakat tersebut.

Selain hasil industri rumah tangga berupa souvenir, wisata kuliner juga bisa dilakukan di Kampung Budaya Betawi Setu Babakan dalam konteks wisata edukasi yaitu untuk mengetahui dan belajar membuat berbagai macam makanan tradisional khas masyarakat Betawi. Beragam makanan, camilan dan minuman khas Betawi seperti; jus belimbing, kerak telor, laksa, toge goreng, gado-gado, dodol, geplak, wajik, rangi, rengginang, ikan pecak, sayur asem, nasi uduk, nasi ulam, nasi begane, tape uli, kue lapis, kure talam, onde-onde dan lain- lain bisa kita temui dengan mudah di Kampung Budaya Betawi Setu Babakan. Wisatawan juga bisa belajar membuat minuman bir pletok melalui paket wisata edukasi yang sudah disiapkan oleh pengelola Kampung Budaya Betawi Setu Babakan.

\section{PENUTUP}

Hakikat dari wisata edukasi adalah memberikan nilai tambah dari kegiatan atau aktivitas yang telah ada di suatu destinasi pariwisata. Keberagaman budaya masyarakat Betawi yang terdapat di Kampung Budaya Betawi Setu Babakan sangat menarik untuk dipelajari. Sejarah masyarakat Betawi yang berasal dari multietnis, penggunaan Bahasa, bentuk arsitektur bangunan serta sejarah bagaimana peranan masyarakat Betawi dijaman dahulu bisa dijadikan sebagai sumber informasi bagi para pelajar yang ingin mengetahui sejarah kebudayaan Betawi melalu wisata edukasi. Kegiatan wisata agro serta 
wisata kuliner Betawi yang unik juga menjadi suatu daya Tarik yang luar biasa yang menjadikan Kampung Budaya Betawi Setu Babakan berpotensi untuk dikembangkan dan layak dijadikan sebagai destinasi wisata edukasi berkelanjutan di wilayah Jakarta.

Sebagai saran, pemasaran serta promosi hendaknya terus dilakukan oleh pihak Kampung Budaya Betawi Setu Babakan bekerjasama dengan instansi terkait agar Kampung Budaya Betawi Setu Babakan dapat lebih dikenal dan diketahui oleh banyak kalangan terutama wisatawan yang ingin melakukan perjalanan wisata dengan tujuan wisata edukasi.

\section{DAFTAR PUSTAKA}

Benur, A. M., \& Bramwell, B. (2015). Tourism product development and product diversification in destinations. Tourism Management, 50, 213-224.

Bodger, D. (1998). Leisure, Learning, and Travel. Journal of Physical Education, Recreation \& Dance, 69(4), 28-31. https://doi.org/10.1080/07303084.1998.10605532

Creswell, J. W. (2016). Research design: pendekatan metode kualitatif, kuantitatif, dan campuran. Pustaka Pelajar.

Gil Arroyo, C., Barbieri, C., \& Rozier Rich, S. (2013). Defining agritourism: A comparative study of stakeholders' perceptions in Missouri and North Carolina. Tourism Management, 37. https://doi.org/10.1016/j.tourman.2012.12.007

Maryetti, Sulistyadi, Y., Damanik, H. D., \& Nurhidayati, F. X. (2016). Pengembangan Berkelanjutan Kampung Budaya Setu Babakan Sebagai Daya Tarik Wisata. Jurnal Destinasi Kepariwisataan Indonesia, 1(1).

Ngwira, C., \& Kankhuni, Z. (2018). What attracts tourists to a destination? Is it attractions. African Journal of Hospitality, Tourism and Leisure, 7(1), 1-19.

Pemerintah Provinsi DKI Jakarta. (2011). Portal Resmi Pemerintah Provinsi DKI Jakarta. https://jakarta.go.id/artikel/konten/2739/betawi-suku123

Pramusita, A., \& Sarinastiti, E. N. (2018). Aspek Sosial Ekonomi Masyarakat Lokal dalam Pengelolaan Desa Wisata Pantai Trisik, Kulonprogo. Jurnal Pariwisata Terapan, 2(1), 14. https://doi.org/10.22146/jpt.35378

Rosmalia, D., Dewi, E. P., \& Putri, R. I. (2019). Potensi Ruang Wisata Budaya Betawi Di Jakarta. IKRA-ITH TEKNOLOGI : Jurnal Sains \& Teknologi, 3(2), 1-10. https://journals.upi-yai.ac.id/index.php/ikraith-teknologi/article/

Santoso, U., Gardjito, M., \& Harmayani, E. (2019). Makanan Tradisional Indonesia Makanan Tradisional yang Populer (Sup, Mi, Set Menu Nasi, Nasi Goreng, dan Makanan Berbasis Sayur). Gadjah Mada University Press.

Sekaran, U., \& Bougie, R. (2016). Research methods for business: A skill building approach. John Wiley \& Sons, Ltd.

Spillane, J. J. (2003). Indonesian tourism: Economic and cultural engineering strategy. Kanisius. 